\title{
The Risk Evaluation of Model Nonpoint-source Agricultural Pollution
}

\author{
DONG DingChao ${ }^{1, a *}$, ZHANG HuiJian ${ }^{1, b}$ and PU WenHui ${ }^{1, c}$ \\ ${ }^{1}$ Science and Technology Information Research Institute,CATAS , Haikou Hainan

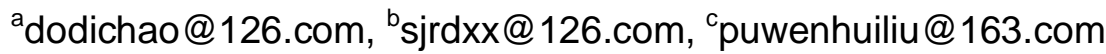

Keywords: the model of risk evaluation; nonpoint-source; agricultural pollution

Abstract. It is difficult to measure non-point source pollution. Compared with other models used in the study of non-point source pollution, INVEST risk assessment is available in agricultural non-point source pollution, which will provide a model for further study of non-point source pollution in large scale space.

\section{The progress of models to assess nonpoint-source agricultural pollution}

Nonpoint-source pollution models might be helpful for us to analyze the spatial and temporal characteristics, identify the main sources and paths, forecast generation load of pollution and the impact on water because complex pollution process has been reported in the system of all basins or regions. Also, the assessments on changes in land use and different technical measures of nonpoint-source pollution and water quality will provide a basis for management decision-making[1].

Recently, there are two ways to forecast model for nonpoint-source pollution load like nitrogen, phosphorus, pesticides and so on. The first method is called as empirical model, including the output coefficient, Universal Soil Loss Equation estimation, correlation, pollution segmentation, rainfall interpolation. The second one is estimated by the introduction of foreign distribution model. The main applications of the pollution load models include CREAMS model, HSPF model, SWAT model, ANSWERS model, etc. [2-8]. These above models mentioned have applied widely on abroad because of high accuracy on simulation. However, there are a lot of parameters in these models, and some of the data are difficult to obtain, for example, we could need long-term monitoring results for water quality and quantity in some models. The lack phenomenon of current basic data, hydrological and meteorological information is serious in China, and the basic investigations on basins are not enough in various cities. The monitoring points of nonpoint-source emissions are set not too much. Thus, the applications and development of models above are restricted.

InVEST ( The Integrate Valuation of Ecosystem Services and Tradeoffs Tool ) was published by combination of Stanford University, TNC and World Wildlife Fund. The aim of InVEST was valuable to mark the natural landscapes on a map[9], and the natural capitals were more easily incorporated into the decision-making system and economic factors and environmental protection can be combined. Now, InVEST becomes a practical analytical tool which will be applied to various fields like environment, water utilities, land resources, and aquaculture. InVEST model can express the quantification of ecosystem services in the form of maps based on GIS, and we don't need cumbersome formula and words any more. The other hand, compared to other models, less data are imported and more data are output in InVEST model. And the model optimizes many complex issues and ultimately resolves problems. InVEST model was multi-level designed with multiple modules and possesses multi-scale, multi-scenario analysis[10]. Meanwhile, water purification module in InVEST model needs fewer input parameters and characteristics data in comparison with others. This module is a set of nesting modules, including water production 
module and nutrient interception module. The water production module is run by the data like the soil thickness, precipitation, soil available water, land use/cover, evapotranspiration, biophysical tables and so on. After that, the outputs, i.e. the average annual water yield is imported in nutrient interception module, can be ultimately simulated into space distribution of nitrogen and phosphorus nutrient loads access into receiving water by raster data analysis.

InVEST model software is convenient based on GIS platform software. The initial spatial data are only imported and a large number of target data can be output through the module. Take the prediction of amount of nutrients in a sedimentary basin as an example, the relevant context will be set firstly, and then the relevant land use map of the target area, the rainfall map, soil depth, drainage basins vector, DEM map and other geographic data will be imported, we can get the value of each sub-basin nutrient output, interception, watershed nutrient output, distribution interception, and the function through the module.

InVEST model has been successfully applied to services and valuation of ecosystem in many countries and regions, such as the United States, California, Hawaii, southern Central America, Ecuador, Venezuela, Colombia, Central America, Belize coast, Asia and Africa, Indonesia, Amazon and Tanzania[11-15]. Thomas Barano et al. calculated the water production nitrogen, phosphorus and other nutrients inputs and outputs of water and vegetation interception in 2008 using water production and nutrient interception modules, and then according to different situations production water, nitrogen and phosphorus output changes, they carried out future ecosystem in Sumatra island based on the data in 2008 .

InVEST model can be applied to assess the ecosystem services and values. We can analyze various scenarios and various objectives and weigh the pros and cons using the model in different contexts like space and time. InVEST models with multiple modules are capable of complex ecosystems comprehensive evaluation. Government and managers can easily regulate natural capitals which are marked on a map on GIS-based platform. And the model is well applied on evaluating the value of ecosystem services in China after being partially amended. However, some disadvantages of applications exist as well. The most serious problem is the lack of space basic data. Therefore, the establishment of a comprehensive spatial database is an important task[16].

\section{Research on agricultural nonpoint-source pollution controls}

Some studies have carried out a lot of agricultural nonpoint-source pollution controls, such as the construction of buffer zones, fertilizer management and so on[17 ]but the construction of agricultural nonpoint-source control projects can not tell the differences between primary and secondary contradictions, unstable control efficiency and high operating costs and other phenomena due to a single structure and system[18].

Zhang et al.[19] analyzed that the point-source and non-point source pollution controls were not classified. According to the current situation in China, they proposed that the source controls in different types of non-point source pollution should be established in a serious water pollution watershed and high pollution risk areas as soon as possible. The production technology standards should be also made based on the local climate, hydrogeology, topography, farmland condition, and reasonable delineation of protected areas in the basin water levels. They also suggested that a "green box" policy should be performed in some areas for encouraging and promoting the widespread adoption of alternative environment protection technologies and production mode so that utilization of agricultural resources will be improved and agricultural technology will be updated. At present, some agricultural nonpoint-source pollution controls include issuing agricultural nonpoint-source pollution control bill, classifying and monitoring pollution, encouraging farmers to adopt environment-friendly production technologies, implementation of technical standards limiting agricultural production in source protection areas, and development on the role of the soft environment. Therefore, we need a comprehensive strategy to guide construction 
of engineering system based on the current agricultural nonpoint-source pollution control engineering[20].

\section{Acknowledgement}

the Fundamental Scientific Research Funds for Chinese Academy of Tropical Agricultural Sciences $(1630012014020)$

\section{References}

[1] Yu Wei Kun, Yin W, Ye Min, et al. Advance Research of Nonpoint Sources Pollution Model[J]. Yangtze River, 2008, 39(23): 83-86.

[2] Bhuyan S J, Koelliker J K, Marzen L J, et al. An integrated approach for water quality assessment of a Kansas watershed[J]. Environmental Modeling\&Software, 2003, 18: 473-484.

[3] Xing K X, Guo H C, Sun Y F, et al. Simulation of Non-point Source Pollution in Dianchi Watershed Based on HSPF Model[J]. China Environmental Science, 2004, 24(22): 229-232.

[4] Cai Ming, Li Huai En, Liu Xiao Jun. Research on Methods of Non-Point Source Pollution Load Estimation. Yellow River, 2007, 29(7): 36 -39.

[5] Abdulla F, Eshtawi T, Assaf H. Assessment of the impact of potential climate change on the water balance of a semiarid watershed[J]. Water Resource Management, 2008, 23(10): 2051-2068.

[6] Zhang Y, Zhang Z Q, Xie Y B, et al. Estimating Methods for Non-point Source Pollution of Small Watershed in Drinking Water Source Area[J]. Science of Soil and Water Conservation, 2009, 7(1): 84-91.

[7] Alarcon V J, McAnally W, Ervin G, et al. Using MODIS land-use/land-cover data and hydrological modeling for estimating nutrient concentrations[A]. In: Taniar D, Gervasi O, Murgante B, et al. (Eds). Computational science and its applicationsICCSA 2010, Part I, LNCS 6016 [C]. Berlin Heidelberg: Springer-Verlag, 2010, 501-514.

[8] Liu Y Q, Yang Y L, Li F H. Estimation of Pollution Loads from Agricultural Nonpoint Sources in Beijing Region Based on Export Coefficient Modeling Approach[J]. Transactions of the Chinese Society of Agricultural Engineering, 2011, 27(7): 7-12.

[9] Kerry A. Dolan. Names You Need To Know In 2011: Natural Capital Project[EB/OL], (2010-11-01). http://www.forbes.com.

[10] Yang Y Y, Dai E F. The Assessment Framework of Ecosystem Service Value Based on INVEST Model[J]. Journal of Capital Normal University(Natural Sciences Edition) , 2012, 33(3): 41-47.

[11] Shaw R. Sierra nevada, California Demonstration Site[EB/OL]. http://www.naturalcapitalproject.org.

[12] Goldstein, J H, Cakdarone G, Colvin C, et al. The natural capital project, Kamehameha Schools, and InVEST: Integrating Ecosystem Services into Land-Use Planning in Hawai i[EB/OL]. http://www.naturalcapitalproject.org/pubs/NatCap_Hawaii_KS_TEEBcase_2010.pdf.

[13]Goldman, R L, Benitez S, Calvache A. et al. Linking People and Nature through Watershed Conservation in the East Cauca Valley, Colombia[EB/OL].

http://www.naturalcapitalproject.org/pubs/NatCap_Colombia_Water_Fund_Demonstration_TEEB_ 2010.pdf.

[14] Goldman R L, Benitez S, Calvache A, et al. water funds: Protecting watersheds for nature and people. Not Peer-reviewed: The Nature Conservnacy Arlington, VA, 2010.

[15] Fisher B, Turner R K, Burgess N D, et. al. Measuring, modeling and mapping ecosystem services in the Eastern Arc Mountains of Tanzania[J]. Progress in Physical Geography, 2011, 35(5): 
595-611.

[16] Turner R. K., Paavola J., Cooper P., et al. Valuing nature: lessons learned and future research directions[J]. Ecological Economics, 2003, 46: 493-510.

[17] Wu Y.H, Hu Z.Y, Yang L.Z. Hierarchical eco-restoration: A systematical approach to removal of COD and dissolved nutrients from an intensive agricultural area [J]. Environmental Pollution, 2010a, 158:3123-3129.

[18] Wu Y.H, Philip G.K, Hu Z.Y, et al. Eco-restoration: Simultaneous nutrient removal from soil and water in a complex residential-cropland area [J]. Environmental Pollution, 2010b, 158:2472-2477.

[19] Zhang W L, Wu Shu Xia,Ji H J, et al. Estimation of Agricultural Non-Point Source Pollution in China and the Alleviating Strategies I .Estimation of Agricultural Non-Point Source Pollution in China in Early 21 Century. Scientia Agricultura in China. 2004a, 37(7): 1008-1017.

[20] Wu Y H, Hu Z Y, Yang L Z. Strategies for Controlling Agricultural Non-point Source Pollution: Reduce-Retain-Restoration(3R) Theory and Its Practice[J]. Transactions of the Chinese Society of Agricultural Engineering, 2011, 27(5): 1-6. 